\title{
UMA PROPOSTA DE REFERENCIAL ANALÍTICO DE GRÁFICOS CARTESIANOS DE CINEMÁTICA A PARTIR DE TABELAS
}

Paulo Sérgio de Camargo Filho*

Carlos Eduardo Laburú* ${ }^{*}$

RESUMO: O estudo propõe a construção de um referencial analítico para a investigação do desempenho de estudantes na produção manual de gráficos cartesianos a partir de tabelas, pautando-se na perspectiva dos registros de representação semiótica, de Raymond Duval, e nos níveis de compreensão da informação gráfica, de Postigo e Pozo. A escolha dos referidos referenciais é relevante, pois o primeiro relaciona as atividades cognitivas às representações semióticas produzidas pelos estudantes, e o segundo permite classificar o domínio da representação gráfica em termos dos níveis de elaboração e complexidade do gráfico produzido. Com base na ferramenta analítica proposta, desenvolveu-se um estudo de caso, considerando para tal fim as produções escritas e entrevistas complementares de estudantes da graduação em Física. Os resultados permitiram classificar o domínio semiótico da representação gráfica com um grau de refinamento analítico superior aos propostos pelos últimos autores.

Palavras-chave: Gráficos Cartesianos. Representação Semiótica. Graduação em Física.

\section{A PROPOSAL OF ANALYTICAL FRAMEWORK TO KINEMATIC'S CARTESIAN GRAPHS FROM TABLES}

ABSTRACT: The study proposes to construct a theoretical framework of analysis to investigate the difficulties of the manual construction of Cartesian graphs for undergraduate degree students in Physics under the light of the theory of semiotic representation registers by Duval and levels of processing graphic information of Postigo and Pozo. The choice of such reference is relevant because the first relates to cognitive activities, semiotic representations produced by students and the second allows you to sort the field of graphical representation in terms of levels of development and complexity of the graph produced. Based on the proposed analytical tool, a case study was developed considering the written productions and additional interviews on graduate students in physics for that purpose. The results classify the semiotic field of the graphical representation with a higher degree of analytical refinement proposed by the latter authors.

Keywords: Cartesian Graphs. Semiotic Representation. Undergraduate Physic.
${ }^{*}$ Doutorando em Ensino de Ciências e Educação Matemática pela Universidade Estadual de Londrina (UEL).

E-mail: ps-camargo@bol.com.br

* *Doutor em Educação pela Universidade de São Paulo (USP), Professor Associado $C$ do Departamento de Física da Universidade Estadual de Londrina (DFUEL). E-mail: laburu@uel.br 


\section{INTRODUC̣ÃO}

O gráfico cartesiano é reconhecido como parte de uma grande variedade de representações simbólicas utilizadas pelos estudantes que, por meio de suas características, estrutura, organização e inter-relações podem influir de forma significativa na aprendizagem de conceitos em Física. De acordo com García e Palácios (2007), diversos pesquisadores reconhecem que as representações gráficas são importantes formas de comunicação científica e ferramentas úteis no campo das ciências experimentais, principalmente na análise de situações físicas nas disciplinas laboratoriais. Segundo esses autores, apesar do uso generalizado que se tem das representações gráficas cartesianas em livros-texto e nas aulas de Ciências na Espanha, a compreensão que os estudantes têm a respeito dessas representações não é a mais adequada. Verificamos que situação semelhante ocorre no Brasil, pois estudantes de licenciatura em Física não são capazes de desenvolver e interpretar gráficos cartesianos de forma satisfatória.

É importante observar que existe um campo de estudo consolidado a respeito da compreensão/interpretação das representações gráficas, do tipo tabela e gráfico cartesiano, usados no ensino de Ciências (Agrello e Garg, 1999; Postigo e Pozo, 2000; Shah e Roefnner, 2002; Araújo, Veit e Moreira, 2004; Wu e Krajcik, 2006; García e Palácios, 2007; Julio, Vaz e Borges, 2008; Belluco e Carvalho, 2009) e na educação matemática (Testa et al, 2002; Duval, 2003; Sharma, 2005; Flores e Moretti, 2006; Miranda, Radford e Gúzman, 2007). Tais autores desenvolveram pesquisas relacionadas à forma como que essas representações são interpretadas ou compreendidas pelos estudantes, no entanto, não se preocuparam em focar seus estudos no modo e nas dificuldades que se apresentam quando essas representações são produzidas.

García e Palacios (2007) investigaram o desempenho dos estudantes de bacharelado e licenciatura em Química em nove tarefas de interpretação de gráficos cartesianos presentes nos livros-texto usados na referida graduação. A pesquisa mostrou que os participantes do estudo não apresentaram impedimentos para realizar as tarefas de identificação das variáveis, leitura de dados e classificação da relação entre as variáveis. Contudo, demonstraram dificuldades em tarefas como a identificação da relação entre as variáveis, o reconhecimento de termos presentes nos gráficos e a elaboração de conclusões, explicações e previsões a partir da informação gráfica.

O trabalho desenvolvido por Flores e Moretti (2006) discutiu as funções cognitivas das representações semióticas que possibilitam a aprendizagem matemática, contribuindo para a compreensão da diversidade e das especificidades de uso das representações gráficas na, e para, a educação matemática. Os autores colocaram em destaque as representações gráficas do tipo tabelas para discutir sua função de suporte representacional de dados e informações no ensino da matemática, e empreenderam uma análise das implicações cognitivas e as complexidades de organização desse modo de representação. O tratamento da informação é, atualmente, 
um dos conteúdos requeridos na educação matemática. Portanto, ler, interpretar, analisar e julgar, ou organizar dados em representações gráficas, são habilidades que se tornaram essenciais para a formação geral do aluno. Contudo, concluem os autores, a própria estrutura das representações gráficas levanta complexidades de leitura e de interpretação que exigem, de nossa parte, certa desenvoltura visual e empenho cognitivo.

Duval (2003) apresentou, em seu trabalho, a maneira como analisar o funcionamento da representação tabela e sua diversidade. Para o autor, as tabelas parecem ser a maneira mais fácil de organizar e comunicar informações, sendo que elas se tornaram um dos recursos preferidos de aprendizagem na educação científica e matemática. No entanto, essa simplicidade é enganadora, pois basta olhar para as tabelas que são utilizadas em diferentes disciplinas para ver que todas elas não funcionam da mesma forma. Em tal estudo, analisou-se a especificidade e a diversidade de tipos de tabelas disponíveis, as funções cognitivas e os problemas educacionais envolvidos em sua utilização. $\mathrm{O}$ autor propôs uma classificação dos diferentes tipos de tabela em relação aos processos cognitivos que controlam sua construção e discutiu a necessidade da aprendizagem de diferentes tipos de matrizes. Duval concluiu que a aprendizagem das representações pesquisadas deve basear-se na atividade de organização de dados na tabela e também na reorganização das margens de uma tabela em conexão com outros tipos de representação.

As preocupações sobre as dificuldades dos alunos compreenderem gráficos em Estatística levaram Sharma (2005) a desenvolver um estudo que investigou as ideias de cinco alunos (de 14-16 anos) nessa área do conhecimento. O estudo centrou-se em apresentar e discutir as formas nas quais os estudantes dão sentido à informação gráfica presente em tabelas e gráficos de barras. Os resultados revelaram que muitos estudantes usaram estratégias baseadas em experiências prévias (cotidianas ou escolares) e estratégias intuitivas, e que, embora os alunos saibam ler e comparar dados presentes em gráficos de barras, eles são menos competentes interpretando tabelas. Isso pode acontecer devido à negligência de instruções desses conceitos ou problemas linguísticos e contextuais, indicando tais dificuldades para pesquisas posteriores.

Alguns pesquisadores focaram seus trabalhos no processo de ensino-aprendizagem da construção e interpretação de gráficos por meio de sequências didáticas. Testa et al (2002) descrevem, em seu estudo, como os alunos do Ensino Médio leem e interpretam imagens que contêm gráficos de cinemática em tempo real, especialmente concebidos para resolver problemas comuns de aprendizagem e minimizar as dificuldades de compreensão e identificação de signos específicos a essa representação, tais como pontos, setas, retas, entre outros. Sugestões foram feitas a respeito da aquisição de algumas habilidades específicas que são necessárias para evitar perdas na interpretação destes gráficos.

Belluco e Carvalho (2009) analisaram a construção da linguagem gráfica em uma sequência de aulas sobre calor e temperatura, inserida em um laboratório investigativo, no primeiro ano do Ensino Médio, destacando o papel do professor 
à medida que ele articula as linguagens disponíveis (oral, escrita, representacional, entre outras) pelos processos de cooperação e especialização, com o objetivo de traduzir a linguagem coloquial e fenomenológica em linguagem científica, no caso, o gráfico cartesiano. Por meio da sequência proposta, concluem os autores, os alunos desenvolveram diversas características da atividade científica, como a natureza do gráfico científico, o reconhecimento de padrões e tendências por meio da curva obtida, a compreensão das flutuações nas medidas, a interpretação do fenômeno usando os conceitos apreendidos, entre outras. A pesquisa aponta para a importância do uso coordenado das linguagens oral, escrita, visual, gestual e matemática, com seus recursos tipológicos e topológicos, articulados com os recursos de cooperação, e da especialização entre elas, para promover uma visão do fenômeno estudado por meio de tais linguagens.

Julio, Vaz e Borges (2008) investigaram o potencial de aprendizagem de alunos da primeira série do Ensino Médio no uso e construção de gráficos para representação de fenômenos observados em atividades abertas de laboratório. $\mathrm{O}$ estudo teve como objetivo caracterizar as dificuldades dos alunos na utilização dos conceitos envolvidos na construção de gráficos e avaliar o potencial de aprendizagem de novos conceitos envolvidos no uso de gráficos para a representação desses fenômenos. A coleta de dados ocorreu no ambiente real de sala de aula de Física, em três turmas de uma escola pública federal que realizaram uma atividade de investigação. Os autores analisaram gravações das aulas, registros sistemáticos de cadernos de campo e gráficos construídos pelos alunos. A análise focou dúvidas, conhecimentos prévios e o potencial de aprendizagem dos alunos sobre os conceitos envolvidos na construção dos gráficos, enquanto buscavam representar o fenômeno observado. Os dados das três turmas foram confrontados para identificar os pontos de convergência com relação às principais dificuldades enfrentadas e a capacidade de sofisticação do entendimento dos conceitos da construção de gráficos pelos alunos. Os resultados revelaram que, ao serem desafiados a construir gráficos para descrever um fenômeno sobre o qual realizavam uma investigação, os alunos demonstraram entendimento dos conceitos básicos da construção de gráficos. Entretanto, esses conceitos básicos não foram suficientes para construir uma representação adequada do fenômeno observado. Frente ao desafio, os alunos foram capazes de pensar criticamente, reconhecendo e interpretando os próprios erros e sofisticaram o seu entendimento sobre os conceitos da construção de gráficos. As conclusões e implicações do estudo apontaram para o potencial das atividades investigativas e de natureza aberta no desenvolvimento de práticas verificar a palavra dos estudantes.

Como visto, existe um crescente corpo de pesquisa que trata de representações gráficas no ensino de Ciências e educação matemática. Dando continuidade às pesquisas referentes a esse tema, propomos um referencial analítico para investigar as dificuldades na construção manual de gráficos cartesianos por graduandos em licenciatura em Física, sob a luz da teoria dos registros de representação semiótica de Duval (2004) e dos níveis de processamento da informação gráfica de Postigo 
e Pozo (2000). Enquanto o primeiro referencial relaciona as atividades cognitivas às representações semióticas produzidas pelos estudantes, o segundo permite classificar o domínio da representação gráfica em termos dos níveis de elaboração e complexidade do gráfico produzido. Para Duval (2003), "uma análise do conhecimento matemático é, essencialmente, uma análise do sistema de produção das representações semióticas" referentes a esse conhecimento. O uso do seu referencial, exclusivo das pesquisas da educação matemática, e que aqui será aplicado num conteúdo de Física, justifica-se pela presença de uma vasta gama de representações utilizadas também para expressar conceitos desse ramo do conhecimento que, com frequência, requerem a transformação e a articulação entre diferentes representações.

Esta pesquisa visa acompanhar, por meio da construção manual de gráficos cartesianos e entrevistas complementares, os processos cognitivos de um grupo de estudantes da graduação em Física, de uma universidade estadual pública do norte do Estado do Paraná. Por meio de tal acompanhamento, buscamos identificar as dificuldades relacionadas à produção e compreensão dos signos pertencentes aos gráficos cartesianos, aplicados no contexto da cinemática. Em conjunto com o referencial de Duval, pretendemos relacionar algumas características gerais e particulares dos gráficos cartesianos com o desempenho que apresentam os estudantes quando realizam a construção dessas representações, classificados de acordo com o nível de processamento da informação gráfica proposto por Postigo e Pozo (2000). Ao reunir os trabalhos de Duval (2003, 2004) com o de Postigo e Pozo (2000), estamos propondo um instrumento analítico para investigar com maior profundidade o desempenho na produção de gráficos pelos estudantes e, por meio desse exame de natureza semiótica, localizar seus pontos de dificuldades.

\section{FUNDAMENTAC̣ÃO TEÓRICA}

Na Física, as leis, teorias, conceitos, modelos, princípios, propriedades, estruturas, relações, são expressas por meio de diferentes modos; portanto, para seu ensino, precisamos levar em consideração as diferentes formas de representação que um mesmo objeto pode assumir. Como em grande parte dessa ciência, assim como toda a comunicação matemática, tais objetos são abstratos e não são diretamente acessíveis à percepção, necessitando-se, para a sua apreensão, do uso de representações semióticas.

As representações semióticas são produções constituídas pelo emprego de signos, pertencentes a um sistema de referência ao qual está associado um conceito ou conjunto de conceitos. São exemplos de signos matemático-científicos a linguagem natural, a língua formal, a escrita algébrica, os gráficos cartesianos, as tabelas, as figuras geométricas, os quais têm suas dificuldades próprias de significado e de funcionamento (DUVAL, 2004). Tais representações são externas e conscientes ao indivíduo, e realizam de maneira indissociável as funções de objetivação e tratamento. 
Um dos papéis desempenhados pelas representações semióticas é o da comunicação, ou seja, o de exteriorizar as representações mentais, tornando-as acessíveis às outras pessoas (ibid.). Além disso, o modo como o aluno elabora ou lida com uma representação semiótica revela, de alguma forma, como ele representou essa informação internamente. Saber interpretar a representação produzida pelo aluno pode ajudar o professor a realizar intervenções mais adequadas no seu processo de construção do conhecimento.

No contexto da Psicologia Cognitiva, Raymond Duval buscou descrever o funcionamento cognitivo do pensamento, considerando, para isso, as mudanças de registros de representação semiótica, o que levou à publicação de diversos trabalhos, entre os quais Sémiosis et penseé humaine: Registres sémiotiques et apprentissages intellectuels (Duval, 2004). No mesmo contexto, Postigo e Pozo (2000) desenvolveram um modelo do funcionamento cognitivo que relaciona as ações de construção/interpretação da informação gráfica ao processamento da informação, resultando no que chamaram de sugiro destacar o termo - itálico ou aspas.

Segundo Postigo e Pozo (2000), a informação gráfica refere-se ao uso de esquemas, tabelas, gráficos, mapas, desenhos, imagens, fotografias. A grande quantidade e variedade dessas informações encontradas ao nosso redor e, em especial, nos diversos níveis do ensino de Física, faz com que a habilidade de processar e tratar essas representações seja essencial para tomar decisões, desenvolver o raciocínio lógico-matemático, além de servir para a comunicação social e científica. Para esses pesquisadores, um critério essencial para diferenciar os distintos tipos de informação gráfica é sua natureza representacional. As representações semióticas têm dois aspectos característicos que estão relacionados com a sua forma (o representante) e o seu conteúdo (o representado), ou seja, o tipo de informação que representam e o formato no qual a representam.

Na Física, por exemplo, as representações semióticas não são apenas indispensáveis para fins de comunicação, mas também são necessárias para o desenvolvimento da própria atividade científica. De maneira mais global, pode-se constatar que a aquisição de conhecimentos é acompanhada sempre da criação e desenvolvimento de sistemas semióticos novos e mais específicos. Assim, a formação de um pensamento científico é inseparável do desenvolvimento de simbolismos específicos para representar os objetos e suas relações.

As representações semióticas, além de estabelecerem a comunicação científica, são necessárias também para as atividades cognitivas do pensamento, ou seja, sem as representações semióticas não é possível efetuar certas funções cognitivas essenciais do pensamento humano. O autor (DUVAL, 2004, p. 35-37) enfatiza três atividades cognitivas fundamentais ligadas à apreensão ou produção de uma representação: a formação de uma representação identificável, o tratamento e a conversão.

A formação de uma representação identificável depende de regras que garantam o reconhecimento das unidades de representações, das suas composições ou de como podem ser combinadas de forma a gerar as regras de tratamento. Para a formação de uma representação, pode-se lançar mão da língua materna, de 
desenhos, figuras ou fórmulas com signos próprios de uma ciência. Um gráfico cartesiano, por exemplo, é identificado, primeiramente, pela presença de eixos cartesianos ortogonais.

O tratamento é atividade cognitiva cuja transformação da representação ocorre dentro do próprio sistema de registro no qual foi formada, como por exemplo, resolver um sistema de equações. As regras de tratamento consideram a transformação da representação no interior do mesmo registro que pertence ao sistema semiótico, mobilizando apenas um só registro de representação. Existem regras de tratamentos próprias a cada registro, e elas variam de um tipo de registro a outro diferente. Os tratamentos são ligados à forma (o representante) e não ao conteúdo do objeto matemático-científico (o representado).

A conversão de uma representação é a atividade cognitiva de transformação de um registro em outro diferente, com regras de formação e tratamento distintos, mas conservando os mesmos objetos denotados. Por exemplo, passar da língua natural à escrita algébrica, ou passar do registro de representação "tabela" ao registro de representação "gráfico" são registros totalmente diferentes que conduzem ao mesmo conceito, porém, têm desempenhos e facilidades cognitivas relativas distintas. A conversão deve compreender a transformação de uma dada representação em outro sistema semiótico, conservando a totalidade ou parte do objeto da representação inicial, sendo necessária a coordenação pelo sujeito que a efetua. A atividade cognitiva de conversão também intervém de forma que o registro no qual os tratamentos a serem efetuados se tornem mais econômicos, mais potentes (Duval, 2003, p. 16), de sorte que um complemente o outro. Do ponto de vista cognitivo, é a conversão que aparece como atividade de transformação fundamental, pois ela "conduz aos mecanismos subjacentes à compreensão" (ibid.).

Com base no que foi exposto, conclui-se que para analisar as dificuldades conceituais, é preciso uma dedicação mais aprofundada aos problemas voltados para a conversão das representações, pois a atividade de conceitualização implica na coordenação entre registros de representação. É necessário que o estudante alcance um estágio de coordenação de sistemas de registros distintos para que possa discriminar o representante e o representado, ou a representação e o conteúdo que a representação expressa ou ilustra (ibid, p. 63). Para isso, o autor propõe que sejam mobilizados, nas aulas, simultaneamente, vários e diferentes registros de representação semiótica para um mesmo objeto.

Postigo e Pozo (2000) centraram-se no estudo das dificuldades que se estabelecem na interpretação da representação gráfica. Embora existam diversas representações da informação quantitativa (tabelas, gráficos de setores, barras, linhas, etc.), em termos gerais os gráficos são representações que apresentam relação numérica entre duas ou mais variáveis por meio de distintos elementos espaciais (células, pontos, barras, linhas, etc.). Segundo os autores, a investigação sobre a aprendizagem de tais representações seria mais bem tratada se considerássemos os níveis de processamento da informação gráfica, com graus de elaboração e profundidade crescentes, incluindo componentes sintáticos e semânticos que 
transcendem uma mera distinção entre informação local e global. Para esses autores, desde a leitura direta de um dado até uma tarefa de resolução de problemas, podem-se distinguir três diferentes níveis de processamento da informação ao construir ou interpretar um gráfico.

O primeiro é o explícito, sendo o nível mais superficial de construção de um gráfico e centrado na produção dos elementos básicos da estrutura gráfica. Por sua vez, a informação implícita pressupõe um nível de processamento que identifica padrões e tendências por meio do estabelecimento de relações entre as variáveis, resultando em procedimentos de maior complexidade que o do nível anterior. A informação conceitual é o terceiro nível de processamento da informação gráfica, centrada no estabelecimento de relações conceituais a partir de uma análise global da estrutura do gráfico. Ela requer ir além da informação contida nos níveis anteriores, e associa-se a outros conhecimentos disponíveis relacionados com o conteúdo representado para realizar interpretações, explicações ou previsões sobre o fenômeno representado no gráfico.

\section{QUADRO TEÓRICO DE ANÁLISE}

Dentro do que foi colocado, procuramos relacionar algumas características gerais e particulares dos gráficos cartesianos com o desempenho que apresentam os estudantes quando realizam a construção dessas representações, classificados de acordo com o nível de processamento da informação gráfica proposto por Postigo e Pozo (2000). Para tais autores, o exame da construção gráfica está baseado nos níveis de processamento da informação explícita, implícita e conceitual, que dependem não somente da habilidade do sujeito em decodificar a sintaxe gráfica e de seus conhecimentos da situação representada, mas também das características intrínsecas da forma gráfica e das ações que permeiam sua construção. Entre esses fatores da atividade de construção/interpretação de um gráfico pelo sujeito, destacamos três grupos de ações as quais são responsáveis pela elaboração da estrutura gráfica, numérica e conceitual. Esses conjuntos de ações são tratados separadamente para melhor compreensão da sua atuação, entretanto, ocorrem simultaneamente na elaboração gráfica, não existindo tal divisão no momento de sua execução.

A estrutura gráfica é formada por ações que produzem elementos básicos de um gráfico. Tal estrutura está relacionada com o nível de compreensão explícito, que é o grau mais superficial de elaboração dessa representação. Nesse nível, as ações que os estudantes realizam são responsáveis por produzir signos que formam a estrutura inicial do gráfico cartesiano, e convertem elementos da representação tabela para a representação gráfica, que corresponde, respectivamente, às atividades cognitivas de formação e conversão, que resulta, por sua vez, numa estrutura gráfica que possibilita a elaboração de estruturas superiores. Inclui-se nas atividades de formação do nível de processamento da informação explícita 
a ação de produção dos eixos coordenados e do título do gráfico, sendo que os eixos devem ser destacados dos demais traços presentes no gráfico e o título deve informar a relação de dependência entre as variáveis. Por meio das atividades de conversão, estabelece-se a escala, as variáveis envolvidas e a localização do par de coordenadas no gráfico cartesiano, com o objetivo de promover a proporcionalidade entre os eixos, auxiliar na leitura do gráfico e estabelecer os pontos coordenados no gráfico, a partir dos dados inicialmente representados na tabela.

A estrutura numérica do gráfico cartesiano é estabelecida por ações que acrescentam novas informações internas por meio da identificação de padrões e tendências entre os signos presentes nessa representação. Tal estrutura relaciona-se com o nível de processamento implícito, que tem um grau de elaboração e complexidade maior que o nível explícito. As ações do nível de processamento da informação implícita são caracterizadas por possibilitar transformações internas ao gráfico cartesiano, correspondendo, portanto, à atividade cognitiva de tratamento. Compete às ações internas a esse registro semiótico a determinação do comportamento da curva e da taxa de variação dos dados, assim como o estabelecimento de novos pontos coordenados.

A estrutura conceitual do gráfico cartesiano é determinada por ações feitas pelo estudante ao generalizar as relações expressas graficamente com o uso articulado do conteúdo semântico com outras formas representacionais acessórias ao gráfico cartesiano, como a linguagem escrita e formal. Tal estrutura relaciona-se com o nível de processamento da informação conceitual, que é o nível mais profundo e complexo da elaboração gráfica. As ações desse nível são caracterizadas por transformar o conteúdo semântico em outras representações semióticas, tal como a escrita literal ou formal, sendo que tal transformação corresponde à atividade cognitiva de conversão. Correspondem às ações da estrutura conceitual a elaboração de legenda, a descrição formal do fenômeno físico e a formulação de explicações por meio de entrevista, as quais explicitem as relações e convenções usadas para a construção do gráfico cartesiano, além de expressar o domínio semântico do conteúdo abordado por essa representação semiótica.

Para uma análise mais minuciosa dos níveis de processamento da informação gráfica, e com o objetivo de qualificar as dificuldades implicadas no processo de construção da representação gráfica, relacionamos os níveis de processamento da informação gráfica às atividades cognitivas semióticas. Assim, estabelecemos um referencial capaz de acompanhar as atividades cognitivas semióticas na realização da representação investigada com os seus respectivos níveis de processamento da informação, e também evidenciar dificuldades na sua produção, caracterizando sua natureza semiótica. Inspirados nos referenciais discutidos, concluímos que para a análise do nível de processamento da informação explícita, deve-se recorrer às atividades cognitivas semióticas de formação e conversão, com as ações dos estudantes voltadas para elaboração da estrutura gráfica. Para análise do nível de processamento da informação implícita, recorre-se às atividades cognitivas de tratamento, com as ações centradas no estabelecimento da estrutura numérica. Para o nível 
de processamento da informação conceitual, recorre-se às atividades cognitivas de conversão, com as ações dos estudantes voltadas para determinação da estrutura conceitual, responsável por evidenciar o domínio semântico do fenômeno físico representado graficamente. No Quadro 1, abaixo, sintetizamos a relação dos níveis de processamento da informação e as correspondentes atividades cognitivas semióticas que caracterizam as ações de construção da estrutura gráfica, numérica e conceitual.

Quadro 1: Quadro Teórico de Análise dos níveis de processamento da informação/atividades cognitivas semióticas e ações construtivas correspondentes.

\begin{tabular}{|c|c|c|}
\hline Nível de Processamento & $\begin{array}{l}\text { Atividade Cognitiva } \\
\text { Semiótica }\end{array}$ & $\begin{array}{l}\text { Ações de } \\
\text { Construção/Interpretação } \\
\text { do Gráfico Cartesiano }\end{array}$ \\
\hline \multirow[t]{5}{*}{ Informação Explícita } & \multirow[t]{2}{*}{ Formação } & Eixos Cartesianos Ortogonais \\
\hline & & Título \\
\hline & \multirow[t]{3}{*}{ Conversão } & Variáveis Envolvidas \\
\hline & & Escala \\
\hline & & Par de Coordenadas \\
\hline \multirow[t]{3}{*}{ Informação Implícita } & \multirow[t]{3}{*}{ Tratamento } & Comportamento da Curva \\
\hline & & Taxa de Variação \\
\hline & & Novos Pares Coordenados \\
\hline \multirow[t]{3}{*}{ Informação Conceitual } & \multirow[t]{3}{*}{ Conversão } & Legenda \\
\hline & & Descição Formal do Fenômeno \\
\hline & & Elaborar Explicações \\
\hline
\end{tabular}

\section{METODOLOGIA}

Para investigar a articulação entre a representação gráfica tabelar e gráfico cartesiano, considerou-se a produção escrita e entrevistas complementares de estudantes de Licenciatura e Bacharelado em Física de uma universidade estadual pública do norte do Estado do Paraná. Do ponto de vista dos procedimentos técnicos, a investigação classificou-se como estudo de caso, pois envolveu o estudo profundo e exaustivo das atividades que permeiam a construção de gráficos cartesianos de cinemática, permitindo um amplo e detalhado conhecimento de tal objeto de estudo (Goldenberg, 2003; Araújo, 2004). Os participantes foram selecionados tendo em conta que já haviam sido aprovados em disciplinas da graduação, tais como Física Básica, Laboratório de Física I e II, nas quais era requisito a aprendizagem da construção manual de gráficos cartesianos de cinemática como parte dos conteúdos curriculares. 
Para as atividades da produção escrita e da construção dos gráficos cartesianos, foram empregadas tabelas de dados experimentais relativas à descrição da posição, velocidade e aceleração de uma partícula, tomados em distintos intervalos de tempo e escolhidas especialmente para essa investigação. Teve-se como objetivo observar o domínio dos signos específicos relacionados às tabelas e sua transformação em signos próprios aos gráficos cartesianos. Com base nas tabelas presentes nas atividades, foi solicitada a resolução de dez itens relativos à construção e compreensão das representações tabela e gráfico cartesiano. Para seleção dos itens que foram desenvolvidos pelos participantes, consideramos as atividades cognitivas semióticas que um estudante deve realizar ao construir manualmente um gráfico cartesiano, conforme estruturado no Quadro 1.

Apresentamos, neste artigo, uma análise realizada com base no Quadro Teórico de Análise, sobre a produção de um dos sujeitos da pesquisa. Tal dado foi escolhido por apresentar uma situação exemplar de aplicação do quadro analítico proposto. Em resumo, investigamos separadamente cada uma das ações de construção gráfica realizada pelo estudante, orientada pelos níveis de processamento da informação e atividade cognitiva semiótica correspondente. Detalhes foram convenientemente evidenciados em figuras para melhor visualização das ações investigadas.

\section{ANÁLISE}

Nessa seção, apresentamos a análise de um dos sujeitos participantes da pesquisa, estudante de Licenciatura em Física, cujos dados foram tomados em $1^{\mathrm{o}}$ de maio de 2010. Inicialmente, evidenciamos o gráfico cartesiano (em parte) e a tabela de referência utilizada pelo estudante para a produção do referido gráfico.

Figura 01: Tabela de Referência e Gráfico Cartesiano correspondente
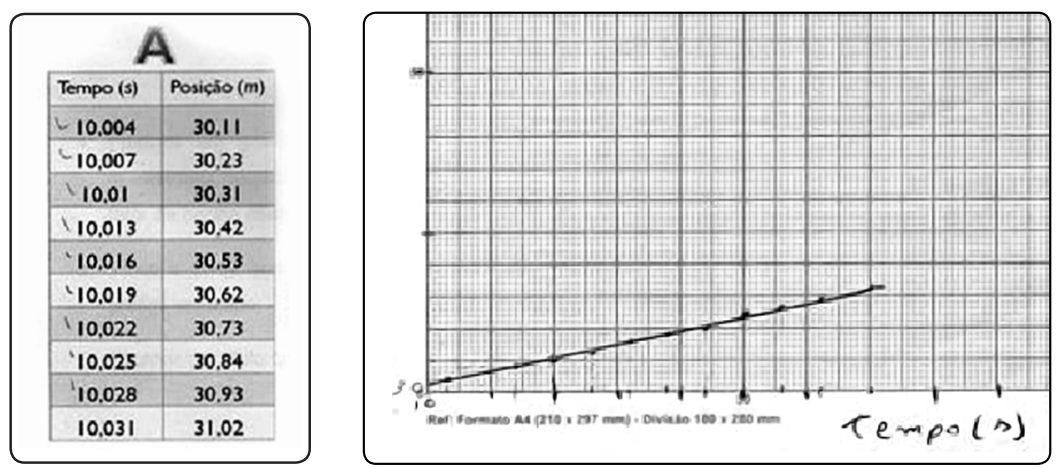

\section{Nível de Processamento da Informação Explícita - Atividade Cognitiva de Formação}

Para a construção inicial da estrutura gráfica, o estudante deveria ter lançado mão das atividades cognitivas de formação no nível de processamento da 
informação explícita. Dessa forma, ele deveria ter traçado os eixos ortogonais, indicando a origem dos pontos; no entanto, os substituiu pelas margens da folha. O estudante também deveria ter recorrido à igual atividade cognitiva semiótica para elaborar o título para o gráfico cartesiano. Os registros do aluno relativos a tais atividades cognitivas podem ser vistos, respectivamente, nas Figuras 2 e 3.

Figura 2: Detalhe do eixo cartesiano horizontal e origem dos pontos

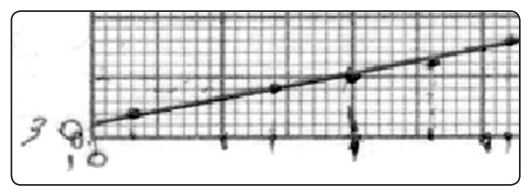

Figura 3: Título do Gráfico

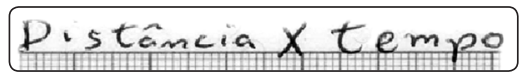

Acrescenta-se que a tabela de referência fornecida para esse estudante não iniciava no ponto $(0 ; 0)$, por esse motivo ele deveria ter realizado um "corte" nos dados e identificado a origem dos pontos. Observa-se, na Figura 2, que tal ação não foi realizada adequadamente, pois o estudante iniciou a escala dos pontos em (10;30). A composição da estrutura gráfica (posteriormente complementada pela transformação de elementos da representação tabela para a representação do gráfico cartesiano) teve como base as margens do papel milimetrado.

\section{Nível de Processamento da Informação Explícita - Atividade Cognitiva de Conversão}

Ao analisar o nível de processamento da informação explícita por meio da atividade cognitiva de conversão, verificamos que, para finalizar a estrutura gráfica, o estudante teve de fazer uma um exame minucioso e qualitativo dos signos presentes na representação tabela e transformá-los em signos próprios para a representação do gráfico cartesiano. Dessa forma, o estudante buscou determinar, por meio da conversão da tabela para o gráfico cartesiano, as variáveis, unidades de medidas e fatores de escala nos eixos cartesianos, conforme observado na Figura 4.

Figura 4: Detalhe do eixo cartesiano horizontal e fator de escala

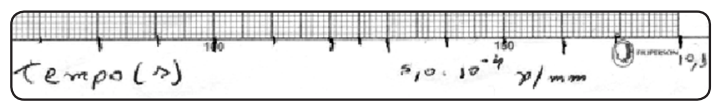

Para determinar o tipo mais adequado de escala, o estudante deveria fazer uma análise global dos valores numéricos presentes em cada coluna da representação tabelar. No entanto, não processou tal ação da forma mais adequada, resultando em um gráfico mal distribuído no espaço de papel que foi determinado para 
tal realização (Figura 01). Observa-se, também, na Figura 4, que ele indicou os fatores multiplicativos sem associá-los aos eixos cartesianos, além disso, não indicou os valores principais da escala e a seta de crescimento dos valores, demonstrando, assim, dificuldades no nível de processamento da informação explícita, na conversão de signos da tabela para sua específica aplicação no gráfico cartesiano. Por fim, a estrutura gráfica foi completada quando houve a transformação dos valores numéricos da tabela em pares ordenados no gráfico cartesiano por meio da atividade cognitiva de conversão.

\section{Nível de Processamento da Informação Implícita - Atividade Cognitiva de Tratamento}

Para a construção da estrutura numérica, o estudante teve de recorrer à atividade cognitiva de tratamento no nível de processamento da informação implícita. A construção de tal estrutura reporta-se às ações relativas à expansão informacional que tem sob si a estrutura gráfica anteriormente elaborada. Dessa forma, o estudante traçou a reta média que julgou mais adequada aos pontos, considerando, para isso, o aspecto regular dos pares ordenados, conforme se observa na figura 5.

Figura 5: Detalhe da reta média

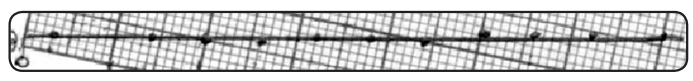

Pela análise das ações relativas às atividades de tratamento para a construção da reta média, verificamos que a reta determinada pelo estudante foi processada de forma adequada. Tendo em vista a Figura 5, a distribuição regular dos pontos foi equivalente em torno dela mesma, no entanto, o seu traçado ficou muito espesso, reduzindo, assim, a sua precisão. A reta média traçada por meio da atividade cognitiva de tratamento possibilitou a determinação de novos pares ordenados, resultando nos valores representados na tabela seguinte.

Tabela de novos pares ordenados determinados pelo estudante

\begin{tabular}{|c|c|}
\hline Tempo (s) & Posição (m) \\
\hline 10,000 & 30,071 \\
\hline 10,0015 & 30,490 \\
\hline 10,0030 & 31,130 \\
\hline
\end{tabular}

O estudante também recorreu à atividade cognitiva de tratamento no nível de processamento da informação implícita para determinar a velocidade escalar média. No entanto, não processou tal ação de forma adequada, pois lançou mão de pares ordenados que não fazem parte da reta média traçada. $\mathrm{O}$ estudante calculou a taxa de variação, no intervalo de tempo estabelecido no 
gráfico, recorrendo a pontos presentes na tabela de referência . Tal desenvolvimento pode ser verificado na Figura 6.

Figura 6: Determinação da velocidade escalar média

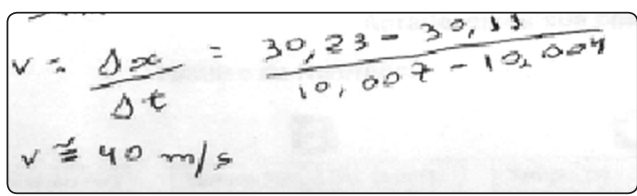

A escolha de pares ordenados pertencentes à tabela para determinar uma propriedade científica do fenômeno demonstra que o estudante não é capaz de articular novas informações (proporcionadas pela reta média) com as demais anteriores. Valendo-se apenas da variação regular do fenômeno, ele chegou a conclusões posteriores a respeito do conteúdo representado sem demonstrar coordenação dos signos presentes na representação do gráfico cartesiano.

\section{Nível de Processamento da Informação Conceitual - Atividade Cognitiva de Conversão}

A investigação das ações relativas ao nível de processamento da informação conceitual por meio da atividade cognitiva de conversão para outras representações semióticas resultou na generalização das relações conceituais aportadas pelo gráfico cartesiano. Isso ficou evidente quando o estudante foi capaz de elaborar uma legenda que expressou, por meio da escrita literal, o movimento uniforme, cuja característica, neste caso, foi a velocidade constante. Para tal elaboração, o estudante se baseou nas relações numéricas desenvolvidas no nível de processamento da informação implícita, por meio das atividades de tratamento. Com base nas mesmas relações, o estudante foi capaz de descrever o fenômeno utilizando a linguagem formal, escolhendo uma equação que expressa corretamente as relações de dependência entre as variáveis. Sendo assim, o tratamento efetuado pelo estudante no nível anterior possibilitou a conversão para outras representações semióticas, mantendo as informações que caracterizam o fenômeno físico.

Figura 3.6: Legenda referente ao gráfico produzido por E03

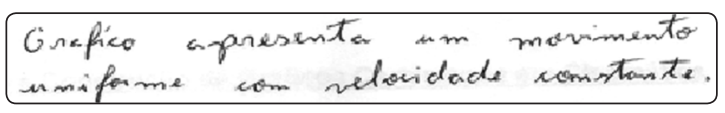

Em entrevista, evidenciou-se que o significado que o estudante atribui à reta média não é o mais adequado, pois ele confundiu a relação entre posição e tempo com a média estatística dos pontos coordenados ao declarar que a reta média significa a "variação da distância em função do tempo, como a distância está variando em função do tempo". Além do mais, o estudante demonstrou não diferenciar os conceitos de posição e distância, demonstrando dificuldades nesse nível de processamento da informação. 


\section{DISCUSSÃO DOS RESULTADOS}

Com base no quadro analítico proposto teoricamente, verificamos que esse estudante não processa algumas regras de formação e de conversão dos signos da tabela para o gráfico cartesiano. Isso foi evidenciado na análise das ações de construção da estrutura gráfica que o estudante realizou, já que ele apresentou dificuldades para o processamento da informação explícita. O estudante demonstrou dificuldades em seguir regras elementares da formação gráfica quando não só deixou de traçar os eixos, os valores principais da escala e as setas que indicariam o crescimento dos valores, mas também por não indicar a origem dos pontos (0;0), não realizando, dessa forma, o ajuste mais adequado dos dados. O estudante também teve dificuldades na conversão dos valores da tabela para o gráfico cartesiano e na produção da escala que melhor distribuía os pontos ao longo dos eixos cartesianos. As dificuldades citadas fazem parte do conjunto de ações responsáveis pela formação da estrutura gráfica, a qual é a base para a elaboração das estruturas superiores do gráfico e também responsável pela visualização, comunicação e compreensão do gráfico cartesiano. Ao investigarmos o título produzido, verificamos que o estudante demonstra uma dificuldade conceitual relativa ao fenômeno estudado, pois atribui o mesmo significado para os conceitos de posição e distância.

Dificuldades também foram encontradas na análise das atividades cognitivas de tratamento. $\mathrm{O}$ estudante demonstrou não coordenar de forma satisfatória os signos da representação do gráfico cartesiano quando recorreu a valores da tabela para calcular a inclinação da reta, não articulando as informações aportadas por meio da reta média com as demais anteriores. A observação da variação regular do fenômeno permitiu realizar conclusões posteriores a respeito do conteúdo representado.

Pela análise das ações responsáveis pela conversão para outras representações no nível de processamento da informação conceitual, pode-se verificar o domínio semântico do fenômeno representado. Apesar de o sujeito da pesquisa ter sido capaz de representar o fenômeno por meio da escrita literal e da linguagem formal, o estudante de graduação não descreve o movimento representado com o rigor e a profundidade esperados para seu nível de formação, não sendo capaz de articular as relações expressas no gráfico para explicar as relações entre as variáveis de forma satisfatória.

\section{CONSIDERACְÕES FINAIS}

O uso do referencial analítico proposto para a análise do trabalho permitiu que fossem acompanhadas as atividades cognitivas do estudante ao transformar a tabela em gráfico cartesiano, segundo o referencial da semiótica. Por meio de tal referencial foi possível verificar o grau de domínio da representação gráfica acompanhada pelas etapas de formação e transformação, podendo categorizá-las em níveis de processamento da informação gráfica, crescentes e mais complexos. 
Além do mais, no processo de análise revelaram-se dificuldades que não seriam evidenciadas se não fosse solicitada a produção de legendas e entrevistas, já que, por meio delas, conhecemos as explicações dos estudantes sobre os signos presentes no gráfico cartesiano.

Configurou-se de modo mais preciso, para o estudo que foi desenvolvido, uma abordagem voltada para o trânsito entre as duas formas de registros de representação gráfica, a tabela e o gráfico cartesiano, visto que eles explicitam de modos diferenciados o mesmo fenômeno físico. Levaram-se em conta resultados de pesquisas que indicaram as dificuldades de compreensão das estruturas que formam a representação do tipo gráfico cartesiana. Diagnosticamos as convergências entre as linhas de pesquisa da Psicologia Cognitiva de Duval e de Postigo e Pozo, as quais resultaram na constituição do Quadro Teórico de Análise. Tal abordagem implicou em uma forma de interpretar mais apurada para enfrentar a problemática proposta, de modo a buscar as relações dos dados pertinentes desse campo conceitual específico.

Nesse sentido, as proposições de Duval relativas às atividades cognitivas semióticas e seu papel na construção de conhecimentos científicos permitiram um melhor aprofundamento na complexidade dos níveis de processamento da informação gráfica. Na perspectiva adotada, a elaboração das tarefas para desenvolver a pesquisa implicou em compreender as estruturas, relações e inferências pertinentes ao sistema tabela e gráfico cartesiano aos quais estão subordinadas às ações de construção realizadas pelos estudantes e subjacentes às diferentes formas de tratamento cognitivo.

As ações relacionadas com a compreensão de signos próprios da representação gráfica possibilitaram não apenas evidenciar o domínio do conteúdo científico, mas também o seu modo de produção. Dessa forma, podemos concluir que as dificuldades centraram-se no registro de representação e não na compreensão do fenômeno físico. As dificuldades apresentadas pelos sujeitos da pesquisa têm características essencialmente semióticas, ou seja, estão relacionadas com o modo com que os estudantes constroem e dão sentido aos signos presentes no gráfico cartesiano.

Por fim, o Quadro Teórico de Análise que apresentamos não tem a pretensão de ser o único instrumento de análise de gráficos cartesianos, pois ainda há questões importantes que englobam o processo de ensino-aprendizagem de tais representações que não foram foco nesta pesquisa, tais como a validade do quadro proposto para a aplicação em outros conteúdos diferentes da cinemática, como gráficos cartesianos de termodinâmica ou eletromagnetismo, e o contexto em que os gráficos cartesianos são ensinados na graduação em Física.

\section{BIBLIOGRAFIA}

AGRELLO, D. A.; GARG, R.. Compreensão de gráficos em cinemática em física introdutória. Revista Brasileira de Ensino de Física, São Paulo, v. 21, n. 4, março 1999.

ARAUJO, I. S.; VEIT, E. A.; MOREIRA, M. A.. Atividades de modelagem computacional no auxílio à interpretação de gráficos da Cinemática. , São Paulo, v. 26, n. 2, pp. 179-184, março 2004. 
BELLUCO A.; CARVALHO A. M. Construindo a linguagem gráfica em uma aula experimental de Física. Ciência \& Educação, Bauru, v.15, n.1, p. 61-84, 2009.

DUVAL, R. Registros de representações semióticas e funcionamento cognitivo da compreensão em matemática. In: Machado, S. A (Org.). Aprendiragem em matemática: registros de representação semiótica. Campinas: Papiros, 2003.

DUVAL, R. Semiosis y pensamiento humano. Registros semioticos y Aprendizajes Intelectuales. Cali, Colômbia: Merlín, I.D. 2004. Título do original: Sémiosis et penseé humaine. Registres sémiotiques et apprentissages intellectuels.

DUVAL, R. Comment analyser Le fonctionnement reoresetationnel dês tableaux et leur diversite? SPIRALE - Revue de Recherches en Éducation, Lille, Faculdade de Ciências da Educação da Universidade Charles de Gaulle, Lille-3, n. 23, 2003.

FLORES C. R.; MORETTI, M. T. O funcionamento cognitivo e semiótico das Representações gráficas: ponto de análise para a aprendizagem matemática. GT: Educação Matemática, São Paulo, n.19. Disponível em: <http://www.ufrrj.br/emanped/paginas/conteudo_producoes/docs_28/ funcionamento.pdf $>$. Acesso em: 20 maio 2010.

GARCÍA, J. J. G.; PALACIOS F. J. P. ¿Comprenden los estudiantes las gráficas cartesianas usadas en los textos de ciencias? Enseñanza de Las Ciencias. Revista de investigación y experiencias didácticas, Barcelona, v. 25, n. 1, p. 107-132, 2007.

ARAÚJO, J. L. (Org.) Pesquisa Qualitativa em Educação Matemática. Belo Horizonte: Autêntica, 2004.

GOLDENBERG, M. A arte de Pesquisar: como fazer pesquisa qualitativa em ciências sociais. 3 ed., Rio de Janeiro: Record, 1999.

JULIO, J.; VAZ, A.; BORGES T. Construção de gráficos em atividade de investigação: microanálise de aulas de física. In: XI ENCONTRO DE PESQUISA EM ENSINO DE FÍSICA, 11., 2008. Curitiba. Anais... Curitiba: SBF, 2008.

MIRANDA, L.; RADFORD, L.; GÚZMAN, J. Interpretación de gráficas cartesianas sobre el movimiento desde el punto de vista de la teoría de la objetivación. Educación Matemática, Barcelona, v. 19, n. 3, 2007.

POSTIGO, Y.; POZO, J.I. Cuando una gráfica vale más que 1.000 datos: la interpretación de gráficas por alumnos adolescentes. Infancia y Aprendizaje, Salamanca, v. 90, p. 89-110, 2000.

SHAH,P; HOEFNNER, J. Review of Graph Comprehension Research: Implications for Instruction. Educational Psychology Review, [s.l], v. 14, n. 1, 2002.

SHARMA S. High School students interpreting tables and graphs: implications for research. International Journal of Science and Mathematics Education, [s.l], v. 4, p. 241-168, 2005.

TESTA, I.; MONROY, G.; SASSI, E. Students' reading images in kinematics: the case of real-time graphs. International Journal of Science Education, [s.1], v. 24, p.235-256, 2002.

WU, H.; KRAJCIK, J. S.. Inscriptional practices in two inquiry-based classrooms: a case study of seventh graders' use of data tables and graphs. Journal of Research in Science Teaching, [s.l] v. 43, n. 1, pp. 63-95, 2006. 
